\title{
Diagnosing acute stroke with magnetic resonance imaging (MRI) calls for caution: computed tomography (CT) is preferable for standard care
}

\author{
Alessandro Squizzato $\cdot$ Lorenzo Moja • \\ Stefano Ricci $\cdot$ Gian Franco Gensini
}

Received: 15 September 2011/Accepted: 16 November 2011/Published online: 27 November 2011 (C) SIMI 2011

\section{Introduction}

This is the second of an unplanned series of articles about the doubts that arise when young doctors have to care for medical experts. The availability and quality of evidence that medical experts have built up may not help novice doctors in friendly clinical decision-making (i.e., whether a treatment will do more good than harm). In the first article we analysed the case of Emeritus Professor Crow, an intermediate-risk patient for pulmonary embolism in whom the benefit of thrombolysis was disputable [1]. Today we face another difficult decision: whether magnetic resonance imaging (MRI) is preferable to computed tomography (CT) for diagnosing acute stroke.

You are the physician on duty at the emergency department (ED), when Professor Peacock, a 71-year-old

A. Squizzato $(\square)$

Department of Clinical Medicine, Research Center on

Thromboembolic Disorders and Antithrombotic Therapies,

University of Insubria, U.O. Medicina I-Ospedale di Circolo,

VialeBorri 57, 21100 Varese, Italy

e-mail: alexsquizzo@libero.it

\section{Moja}

Department of Public Health, Microbiology and Virology,

University of Milan, Milan, Italy

L. Moja

Mario Negri Institute for Pharmacological Research, Milan, Italy

S. Ricci

Division of Neurology, Stroke Unit,

ASL 1 Umbria, Città di Castello, Perugia, Italy

G. F. Gensini

Department of Critical Care Medicine and Surgery,

University of Florence and Azienda

Ospedaliero-Universitaria Careggi, Florence, Italy professor of neurology, enters with a right hemiplegia [2]. While starting to collect clinical data and ordering studies, you remember that, five years ago, you attended Prof. Peacock's speech at the National Stroke Conference. As he is supposed to be a field expert in stroke management, you feel under pressure. You would like to engage Prof. Peacock in every phase of diagnosis and treatment: the physician-patient is well-informed, and his decision may follow different strategies from less-informed patients [3]. Then too, you are well aware that, to disseminate their opinions and dominance, experts commonly disagree with young doctors, so it would be wise to listen to his advice. Unfortunately, he is aphasic.

As his wife reports, he started complaining about walking and other motor disorders about an hour prior to admission. There is still time for thrombolysis, if there are no contraindications. The resident on duty, who recently attended a course on neuroimaging, recalls that MRI is excellent for identifying ischemic brain lesions. 'We should offer him the most recent and innovative management', the resident is convinced. 'I've never requested an MRI for a suspected acute stroke' you reply in a low voice, adding 'What if there is a brain haemorrhage? Are you sure MRI is sufficiently sensitive in identifying cerebral bleeding?' 'No data were presented, only opinions' the resident whispers. Despite the low voice, Prof. Peacock's wife understands the doubt we are facing. She confidently presents a conclusion based on implicit values about the best: 'He needs a cerebral MRI' cutting off any further discussion for a moment.

You are astonished. 'Am I acting like a stubborn old physician refusing to utilise new technologies, or are the experts blindly trusting that new technologies can only be beneficial?' Before calling the stroke experts on duty, you decide to take a quiet look at the Cochrane Library. The 
title seems fitting: 'Magnetic resonance imaging vs. computed tomography for detection of acute vascular lesions in patients presenting with stroke symptoms' [4]. You open the systematic review on the computer screen.

\section{The Cochrane point of view: a systematic review}

The authors did this review to compare the diagnostic accuracy of cerebral diffusion-weighted (DWI) MRI or CT in detecting ischemic lesions caused by acute ischemic stroke, and to estimate the diagnostic accuracy of MRI for acute haemorrhagic stroke [4]. Eight studies with a total of 308 participants were identified. Seven studies were used for the assessment of ischemic stroke, and two for haemorrhagic stroke. In all the studies, the spectrum of patients was relatively narrow, the samples were small, there was substantial incorporation bias (i.e., when the MRI test under consideration is used to determine the reference standard, or the reference standard is used to determine the results of the diagnostic test) [5], and blinding procedures for outcome assessors were often incomplete.

In patients with an acute ischemic stroke, the summary estimates for DWI MRI are: sensitivity 0.99 (95\% CI $0.23-1.00)$ and specificity 0.92 (95\% CI $0.83-0.97)$ [4]. You feel the sensitivity is high but the confidence interval is wide and includes values that are far from optimal. The summary estimates for CT are: sensitivity 0.39 (95\% CI $0.16-0.69)$ and specificity 1.00 (95\% CI $0.94-1.00)$ [4]. The specificity is excellent, and the confidence interval is narrow.

The two studies on haemorrhagic stroke report high estimates for DWI and gradient-echo sequences, but have inconsistent reference standards. The authors did not calculate overall estimates for these two studies, and were not able to assess how practical or cost-effective they were [4]. They speculate that DWI MRI appeared to be more sensitive than CT for the early detection of ischemic stroke in highly selected patients [4]. Is this conclusion a matter for an emergency physician? The characteristics of the patient population were not a representative of the typical population being assessed for thrombolysis. First, all but one study included a very narrow spectrum of patients with typical anterior circulation stroke and limited severity. Moreover, the study with a wider spectrum of patients still only included mostly mild strokes (median National Institutes of Health Stroke Scale [NIHSS = 3], scale ranges from 0 to 42, maximal severity) [6]. Patients with severe stroke who often do not tolerate MRI were not eligible [6]. Second, the information on other patients who were excluded because they either could not tolerate MRI or had contraindications (e.g., pacemakers and metal implants), was provided in only three studies [4]. About $11 \%$ of the patients initially screened for inclusion were subsequently excluded in the largest study [6]. Third, in most studies, patients with stroke mimicking diseases (for example cerebral neoplasms or systemic infections) were also not included in the spectrum of interest [4]. The sample was in fact a poor representative of the acute patients typically seen in an ED, where 15-30\% with an initial clinical diagnosis of stroke are ultimately found to have strokemimicking pathologies. All these limitations make it difficult to translate the estimates of accuracy provided by the meta-analyses to routine clinical practice [4]. In fact, the review authors conclude 'In particular, further studies are needed to provide clear evidence that MRI can be used as the imaging modality of first choice for patients with suspected acute stroke in routine practice, and that patients without evidence of acute intracerebral haemorrhage on MRI really do not have acute intracranial bleeding, and hence can be safely considered for thrombolytic treatments' [4].

\section{The stroke expert's point of view: clinical guidelines}

The four most recent guidelines are provided by the Therapeutics and Technology Assessment Subcommittee of the American Academy of Neurology, by the National Institute for Clinical Excellence (NICE), by the Italian SPREAD Group and the Scottish Intercollegiate Guidelines Network (SIGN) [7-10]. The first guideline is rather vague in suggesting which test should be preferred (assuming there is one): instead of pointing out where evidence is lacking or inadequate, guideline authors speculate 'above' the evidence. In particular, panellists state: 'DWI MRI is established as useful, and should be considered more useful than non-contrast CT for the diagnosis of acute ischemic stroke within $12 \mathrm{~h}$ of symptom onset. DWI MRI should be performed for the most accurate diagnosis of acute ischemic stroke; however, the sensitivity of DWI MRI for the diagnosis of ischemic stroke in a general sample of patients with possible acute stroke is not perfect. There is insufficient evidence to support or refute the value of perfusion weighted imaging (PWI) in diagnosing acute ischemic stroke' [7]. But, most importantly, they write: 'The diagnostic accuracy of DWI MRI in evaluating cerebral haemorrhage is outside the scope of this guideline' [7]. For urgent brain imaging, the recommendation promoted by the NICE supports DWI MRI [8].Conversely, the SPREAD group firmly states "Cerebral CT without contrast is suggested as soon as possible at the ED to differentiate stroke from stroke-mimicking pathologies, and haemorrhagic stroke from ischemic stroke; and to identify early signs of cerebral ischemia' [9]. SIGN's recommendation similarly favours CT over DWI MRI [10]. 
Table 1 Main inclusion and exclusion criteria for thrombolysis in patients with acute ischemic stroke. [11]

\begin{tabular}{|c|c|}
\hline Inclusion criteria & Exclusion criteria \\
\hline Age $\geq 18$ years & Minor or rapidly improving symptoms or signs \\
\hline $\begin{array}{l}\text { Clinical diagnosis of stroke with clinically } \\
\text { meaningful neurologic deficit }\end{array}$ & CT signs of intracranial haemorrhage \\
\hline Clearly defined time of onset before treatment & History of intracranial haemorrhage or symptoms of subarachnoid haemorrhage \\
\hline \multirow{5}{*}{$\begin{array}{l}\text { Baseline CT showing no evidence of intracranial } \\
\text { haemorrhage }\end{array}$} & Seizure at stroke onset \\
\hline & Stroke or serious head injury within 3 months \\
\hline & $\begin{array}{l}\text { Recent history of major surgery, serious trauma, or gastrointestinal or urinary tract } \\
\text { haemorrhage }\end{array}$ \\
\hline & Systolic BP $>185 \mathrm{mmHg} /$ diastolic $\mathrm{BP}>110 \mathrm{mmHg}$; glucose $<50 \mathrm{mg} / \mathrm{dL}$ or $>400 \mathrm{mg} / \mathrm{dL}$ \\
\hline & $\begin{array}{l}\text { Heparin therapy within } 48 \mathrm{~h} \text { associated with elevated activated partial thromboplastin time; } \\
\text { anticoagulation due to oral anticoagulants (international normalized ratio [INR }>1.7] \text { ) }\end{array}$ \\
\hline
\end{tabular}

\section{Conclusion}

Waiting for the stroke expert, you decide that a cerebral CT should be the first choice. You approach Prof. Peacock's wife to deal with her anxieties, and tell her, first, what her husband might have, and second, what not to expect from an MRI, and what to expect from a CT scan. A small subdural haemorrhage is detected in the right temporal area. There are no signs of ischemia.

A few minutes later, the neurologist from the stroke team arrives. 'My husband urgently needs your help!' The specialist carefully examines Prof. Peacock. After viewing the clinical record and cerebral CT, he prints thrombolysis inclusion and exclusion criteria (see Table 1) [11]. He invites Prof. Peacock's wife to sit down, and starts kindly to explain: 'Let me tell you about the possible risks and benefits of thrombolysis ...'?

Professor Peacock has been lucky despite the limited directness of the evidence, its low quality and the presence of a young doctor. All these elements could interfere with the clinical decision-making, giving precedence to the diagnostic test that might have led to a treatment that would do more harm than good.

Conflict of interest The authors declare that they have no conflict of interest related to the publication of this manuscript.

\section{References}

1. Squizzato A, Moja L, Gensini GF, Gusinu R, Conti AA (2009) Is thrombolysis for intermediate-risk pulmonary embolism beneficial? The case of Emeritus Professor Crow. Intern Emerg Med 4:339-341

2. Oxman AD, Chalmers I, Liberati A (2004) A field guide to experts. BMJ 329:1460-1463
3. Domenighetti G, Casabianca A, Gutzwiller F, Martinoli S et al (1993) Revisiting the most informed consumer of surgical services: the physician-patient. Int J Technol Assess Health Care. 9:505-513

4. Brazzelli M, Sandercock PA, Chappell FM, Celani MG, Righetti E, Arestis N,Wardlaw JM, Deeks JJ (2009) Magnetic resonance imaging versus computed tomography for detection of acute vascular lesions in patients presenting with stroke symptoms. Cochrane Database Syst Rev. CD007424

5. Worster A, Carpenter C (2008) Incorporation bias in studies of diagnostic tests: how to avoid being biased about bias. CJEM 10:174-175

6. Chalela JA, Kidwell CS, Nentwich LN, Luby M, Butman JA, Demchuk AM et al (2007) Magnetic resonance imaging and computed tomography in emergency assessment of patients with suspected acute stroke: a prospective comparison. Lancet 369: 293-298

7. Schellinger PD, Bryan RN, Caplan LR, Detre JA, Edelman RR, Jaigobin C, Kidwell CS, Mohr JP, Sloan M, Sorensen AG, Warach S et al (2010) Therapeutics and Technology Assessment Subcommittee of the American Academy of Neurology. Evidence-based guideline: the role of diffusion and perfusion MRI for the diagnosis of acute ischemic stroke: report of the Therapeutics and Technology Assessment Subcommittee of the American Academy of Neurology. Neurology 75:177-185

8. SPREAD group. Ictus cerebrale: lineeguidaitaliane di prevenzione e trattamento. www.spread.it Last access 31 January 2011

9. National Collaborating Centre for Chronic Conditions. Stroke: national clinical guideline for diagnosis and initial management of acute stroke and transient ischaemic attack (TIA). London: Royal College of Physicians, 2008

10. Scottish Intercollegiate Guidelines Network (SIGN). Management of patients with stroke or TIA: assessment, investigation, immediate management and secondary prevention. Edinburgh: National Health System Scotland, 2008

11. Albers GW, Amarenco P, Easton JD, Sacco RL (2008) Teal P: American College of Chest Physicians. Antithrombotic and thrombolytic therapy for ischemic stroke: American College of Chest Physicians Evidence-Based Clinical Practice Guidelines (8th Edition). Chest 133(6 suppl):630S-669S 